\title{
Impact of 60 Years of Intensive Rice Cropping on Clay Minerals in Soils Due to Si Exportation
}

\author{
Kamran $\operatorname{Irfan}^{1}$, Fabienne Trolard ${ }^{1,}$, Tanvir Shahzad ${ }^{2}$, Lise Cary ${ }^{3}$, Jean-Claude Mouret ${ }^{4}$, \\ Guilhem Bourrié ${ }^{1}$ \\ ${ }^{1}$ INRA (National Institute of Research in Agronomy), Université d'Avignon et des Pays du Vaucluse, UMR Emmah, Avignon, France \\ ${ }^{2}$ Department of Environmental Sciences \& Engineering, Government College University Faisalabad, Faisalabad, Pakistan \\ ${ }^{3}$ BRGM (French Geological Survey), Nord Pas-de-Calais Regional Direction, Lezennes, France \\ ${ }^{4}$ INRA (National Institute of Research in Agronomy), IRD (Institute of Research \& Development), SupAgro Monptellier, UMR Innovation, \\ Montpellier, France
}

\section{Email address: \\ fabienne.trolard@inra.fr (F. Trolard) \\ *Corresponding author}

\section{To cite this article:}

Kamran Irfan, Fabienne Trolard, Tanvir Shahzad, Lise Cary, Jean-Claude Mouret, Guilhem Bourrié. Impact of 60 Years of Intensive Rice Cropping on Clay Minerals in Soils Due to Si Exportation. American Journal of Agriculture and Forestry. Vol. 5, No. 3, 2017 , pp. 40-48. doi: 10.11648/j.ajaf.20170503.12

Received: February 2, 2017; Accepted: February 17, 2017; Published: April 14, 2017

\begin{abstract}
Rice is cultivated as staple for over half of the World's population. In Camargue (South of France) rice fields have been established on very young soils developed from historic fluvial deposits of the Rhône River. The comparison of clay mineralogy in a paddy field cultivated for 60 years and in a control shows a significant increase of the clay crystallinity in the paddy field soil, which implies a decrease of their solubility. In the paddy soils, phytoliths, poorly crystallized clays, such as smectite and to a lesser extent kaolinite, are progressively dissolved to supply Si for rice requirements. The sustainability of the crop system requires the clearing of silica exportations.
\end{abstract}

Keywords: Clays, Crystallinity, Rice, Silicon

\section{Introduction}

Rice is cultivated as staple for over half of the World's population. After a marked improvement thanks to the green revolution, grain yields today tend to level off or even decline, production environments are being degraded progressively and water resources and soils are increasingly scarce, while food demand is increasing [1].

Silicon is the second most abundant element in the Earth's crust after oxygen [2]. In primary minerals or secondary minerals, $\mathrm{Si}$ is always combined with oxygen and forms mainly quartz and silicates. The solubility of quartz is very low in comparison with other silicates [3] therefore it is not readily available for plants [4]. The clay fraction (particles $<$ $2 \mu \mathrm{m})$ constitutes the principal source of Si nutrient reserve $[5,6]$ and consists of clay minerals and of Si-biogenic particles.

The importance of the biogenic cycle of silicon in terrestrial environments has been clearly recognized [7, 8]. For instance, we know that the solubility of Si-biogenic particles is similar to that of amorphous silica $[9,10]$ but much larger than that of quartz or silicates $[11,12]$.

The main forms of $\mathrm{Si}$ in plants, i.e, extra or intracellular silica deposits often referred to as phytoliths, are opal-A [13, $14,15,16]$. Si constitutes from 0.1 to $10 \%$ of the dry matter in the majority of plants and this content varies depending on the species and the characteristics of the environment where plants grow $[15,17]$. Comparison with contents of $\mathrm{Ca}(0.1$ to $0.6 \%), \mathrm{S}(0.1$ to $1.5 \%), \mathrm{N}(0.5$ to $6 \%), \mathrm{P}(0.15$ to $0.5 \%)$ and $\mathrm{K}(0.8$ to $8 \%)$ showed that $\mathrm{Si}$ in plants could be present in an equivalent amount, or even larger than several macronutrients [17]. Si accumulated in the plant maintains the structure of the stem, prevents lodging, organizes aerial architecture for better perception of light, protects against herbivore attacks, limits aluminium and manganese toxicity, increases resistance to salt and heating stresses and 
contributes positively to yield by limiting intrusion of problematic toxic elements such as arsenic, antimony or cadmium [18]. Grasses have high phytolith contents and some wetland plant species, such as rice and phragmites, are typical Si-accumulators where Si content amounts to $10-15 \%$ $[17,19]$. In natural ecosystems, phytoliths are deposited upon plant death and decomposition in soil, where their abundance is regulated by the balance between plant inputs and dissolution outputs, which are controlled by the degree of chemical weathering [7, 20], soil mineralogy [21] and bioclimatic conditions [22]. In agro-systems, the cultivation and harvest of crops may export 50 to $100 \mathrm{~kg} \mathrm{Si} \mathrm{ha}^{-1}$ each year out of the fields [6], which can be a possible cause of declining rice yields [23] and produce a decrease of soil amorphous silica by long-term removal of wheat straw [24]. Thus, the effect of Si deficiency on rice growth and of different methods of fertilization has been investigated (e.g. see synthesis by $[18,19]$. However, the impact of rice crops on the mineralogy of silicate minerals of soil has not been thoroughly investigated because it is assumed that soils contain large amounts of Si so that this is not a limiting factor [25].

The aim of this study is to compare the mineralogy of clay fractions in a paddy field under rice cultivation for 60 years with a control, a fallow with phragmites, both in the same soil unit.

\section{Materiel}

\subsection{Context of Study Area}

The site of study is a rice cropping area, in Southern France (Camargue) (Fig. 1). It is located in the Western part of the Mediterranean basin between two branches of the Rhône River delta [26]. It is an alluvial plain of 142,000 ha, sub-horizontal plane with average slope of $0.017 \%$ from North to South, Latitude $43^{\circ} 34^{\prime} \mathrm{N}$ and Longitude $4^{\circ} 34^{\prime} \mathrm{E}$. The rice production in this area is thought to have started in 1860 with the rapid accumulation of salts as a consequence of damming in this region. Dams were built to protect the nearby population from flooding. Before World War II (1939-1945), rice cultivation was not very popular. However, it was promoted after the rice shortage caused by World War II. It has been supported by guaranteed price and funds from the Marshall Plan in 1947 and by the agricultural equipment cooperative established in 1948. It has been an integral crop in this region for over 60 years, sometimes in rotation with wheat crops and temporary pastures [27]. Generally, one crop of rice (Oryza sativa L.) is grown per year from May to October under flooded conditions while, during the rest of the period, fields are left fallow.

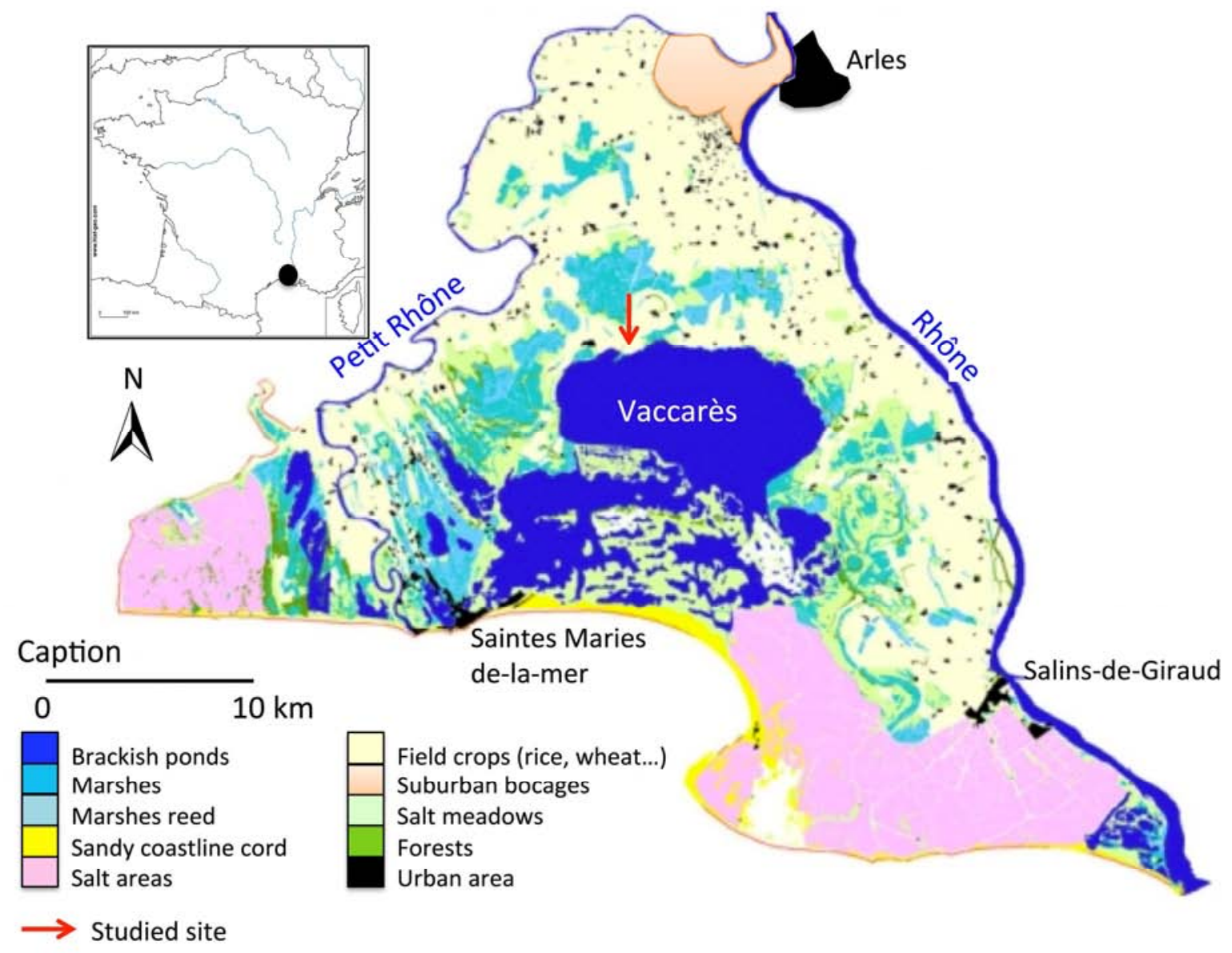

Figure 1. Landscape units in Camargue area, South-East of France (from SNPN-Réserve Nationale de Camargue) and location of the study site. 
Camargue's soils belong to soil families, which have fluvial origin and differ in the detail by small variations of altitude above the sea level [28]. Large lateral differences occur, due to the presence of paleo-channels of the Rhône River where paddy fields where firstly settled due to their slight higher altitude. These soils are conditioned by fluctuations in saline surface water table and waterlogging. Salinization and hydromorphy are controlled by human activities such as agriculture and the salt industry. The flood irrigation in rice fields helps to control salt levels in the soil thereby making it possible to grow crops susceptible to salts such as wheat or vines. Loamy clay, clayey loam and clayeysandy loam are the main soil textures in rice fields of this region [29].

\subsection{Soil Samples}

Two plots were chosen, one where rice cultivation has been continued for the last 60 years, while the other remained fallow for the same duration [30, 31]. Vegetation in the fallow plot changed when the paddy fields were created, passing from natural "sansouïre" vegetation to phragmites (X. Guillot, personal communication). The soils in both plots were developed in recent fluvial deposits of the Rhône River (6500-4000 BP) [32] and are young, close to sedimentary deposits. Soils were sampled at discrete depths between 5 and $100 \mathrm{~cm}$ both in the paddy and the fallow fields. Rareearth elements (REE) analyses show that both soils developed from the same parent material and underwent the same pedogenetical evolution [30]. Twenty samples were taken and an X-ray diffraction analysis of the clay fraction was performed.

\section{Methods}

\subsection{Pre-Treatments and Sample Preparation for XRD Studies}

Bulk soil samples were air dried, crushed, disintegrated by ultrasound and sieved to $50 \mu \mathrm{m}$. Carbonates were dissolved by reaction with a $5 \% \mathrm{HCl}$ solution and the organic material was destroyed with a $30 \% \mathrm{H}_{2} \mathrm{O}_{2}$ solution. The residual solid fraction was suspended in water in calibrated devices during 8 hours. The upper ten centimetres of the suspensions, containing the fraction smaller than $2 \mu \mathrm{m}$, were extracted. The material was centrifuged at 4,000 rpm during 5 minutes and then small amount of suspension was deposited on four glass slides followed by air-drying.

Orienting the sheets on a glass slide enhances the signal of (001) lattice spacing of clay minerals [33]. One oriented sample was passed directly to give the reference X-ray pattern of the clay fraction. In addition, the following pretreatments were applied: (i) with hydrazine (Hy treated sample) the main peak of kaolinite at $7 \AA$ shifts to $10.4 \AA$ [34], which allows for differentiating kaolinite from chlorite; (ii) with ethylene glycol (EG treated sample) some 2/1 minerals swell and thus, for example, the peak of smectites at 13 to 15
$\AA$ shifts to $17 \AA[35]$ and (iii) by heating at $490^{\circ} \mathrm{C}$ the peaks from chlorite are refined.

\subsection{XRD Diffraction}

X-ray diffraction patterns were recorded with an analytical PW 1729 Philips X'pert Pro diffractometer equipped with a

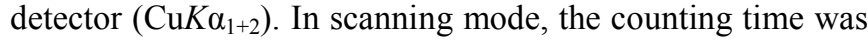
$2 \mathrm{~s}$ by step size of $0.05^{\circ}$ in a $2 \theta$-interval from 2.5 to $35^{\circ}$. To refine the signal, samples treated by ethylene - glycol were passed a second time with $10 \mathrm{~s}$ by step size of $0.02^{\circ}$ in the interval from 2.5 to $18^{\circ}$.

\subsection{DecompXR Analysis}

The DecompXR software [36] allows for peak decomposition of XRD patterns, for refining the peak position, the full width at half maximum intensity (FWHM), and relative intensities or profile shape [37]. It is particularly useful for clay fraction analysis where the well-known conflict of peak widths in the range of $5-11^{\circ} 2 \theta-\mathrm{CuK \alpha}(17.6-$ $8.0 \AA)$ is often observed. The DecompXR software was used for clay-mineral identifications and the FWHM parameter was calculated for the estimation of the degree of crystallisation of the clay minerals, which depends on the size of the domain of coherent scattering [38].

The extraction of necessary information consists of three steps: (i) correction of experimental noise by smoothing algorithm, (ii) choice of the angular area with the probability of the peaks representing the minerals to be estimated, (iii) reconstitution of the signal by the sum of theoretical peaks computed by Lorentzian or Gaussian functions in refined position.

Angular area used to determine FWHM parameters ranges between 5 and $16^{\circ} 2 \theta$ on ethylene - glycol treated patterns for smectite, chlorite and illite and on hydrazine treated patterns for kaolinite. The initial values of position, width, intensity and the shape of the peak parameters are arbitrarily fixed and the quality of the fit was estimated after iterations. The calculation was stopped and computed fits considered as valid when the reliability factor amounted to $99 \%$.
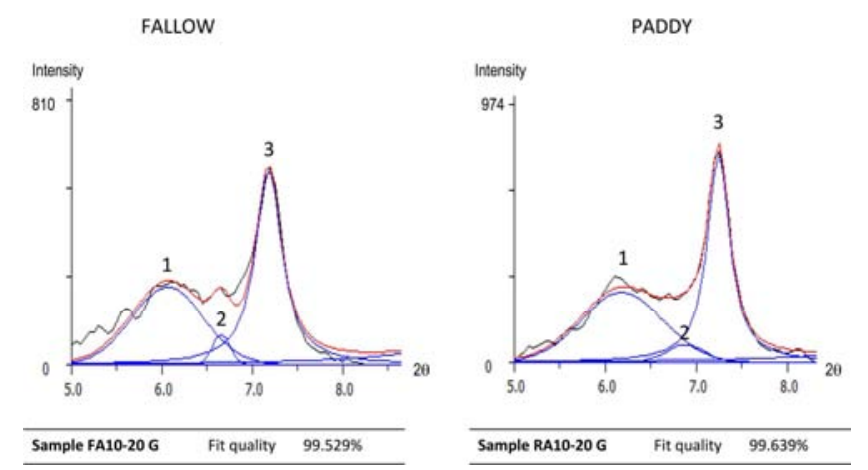

Figure 2. Examples of DecompXR deconvolution results obtained on Ethylene-Glycol treated patterns from 10-20 cm depth samples. Peak 1 is assigned to smectite and peak 3 to chlorite. Black line = experimental pattern, blue line $=$ Gaussian or Lorienztian functions, red line $=$ calculated pattern. 
Table 1. Examples of result of DecompXR analysis: samples RA10-20G (paddy) and FA10-20G (fallow).

\begin{tabular}{llll}
\hline Parameter & Peak 1 & Peak 2 & Peak 3 \\
\hline Sample RA10-20G & & & \\
Peak position (20) & 6.17 & 6.87 & 7.24 \\
Intensity & 176.02 & 44.84 & 526.40 \\
FWHM & 0.985 & 0.492 & 0.381 \\
Peak shape & Gaussian & Lorentzian & Lorentzian \\
Reliability factor & $99.64 \%$ & $99.64 \%$ & $99.64 \%$ \\
Sample FA10-20G & & & \\
Peak position ((20) & 6.16 & 6.65 & 7.19 \\
Intensity & 157.64 & 62.58 & 399.33 \\
FWHM & 1.687 & 0.219 & 0.351 \\
Peak shape & Gaussian & Lorentzian & Lorentzian \\
Reliability factor & $99.53 \%$ & $99.53 \%$ & $99.53 \%$ \\
\hline
\end{tabular}

FWHM $=$ Peak width at half of the length

The estimation of the degree of crystallization of the principal clay minerals is based on the analysis of the relative variation of FWHM parameter calculated by the DecompXR software on the main peaks of each clay fraction. The larger the FWHM the poorer the degree of crystallization of clay minerals; Fig. 2 and Table 1 present an example of FWHM computed from X-ray pattern of EG treated samples. Thus on our example (Fig. 2), the refined peak 1 is ascribed to smectite and peak 3 to chlorite. For this first analysis of results, calculated peaks, which can be ascribed to the likely presence of some interstratified illite-smectite, such as peak 2 , are not analyzed here.

\subsection{SEM and TEM Imageries}

Pictures were recorded with a scanning electron microscope (SEM) equipped with an energy dispersive spectrometer (EDS) and a transmission electron microscope (TEM) in the CRMCN (Centre de Recherche sur la Matière Condensée et Nanosciences) at Marseilles (France). From the clay fraction of soils, clay particles were observed by TEM and Si-biogenic particles were observed by SEM after extraction by Kelly's protocol [39, 40].

\section{Results and Discussion}

\subsection{Comparison of the Two Systems in Term of Si-Cycle}

Although developed in the same unit of soil, the paddy field and the fallow with phragmites differ by tillage realized by the farmer in the paddy field [31] (Fig. 3). This tillage consists in creating a plough pan almost impervious between 35 and $50 \mathrm{~cm}$ depth in order to maintain the flooding of the rice field while saving irrigation water [41].

Both phragmites and rice are $\mathrm{Si}$-accumulative plants, but in the fallow with phragmites, the Si-cycle can be considered as closed and the system operates in steady state, while in the paddy field the cycle is clearly open due to crop exportation. During vegetation growth plants take up large amounts of $\mathrm{Si}$ every year, while a part of $\mathrm{Si}$ is supplied by irrigation water input or dust deposition [42]. In autumn, large amounts of $\mathrm{Si}$ present in rice straw and cuticle of grains are exported along with the rice crop, while in the fallow phragmites fall and their litter is deposited into the soil where it is extensively degraded during winter due to flooded conditions and alkaline $\mathrm{pH}$. In Camargue, a preliminary balance in the paddy system pointed out that at least $270 \pm 80 \mathrm{~kg} \mathrm{Si} \mathrm{ha}^{-1}$ year $^{-1}$ are exported out of the field [42], which cannot be compensated by the significant suspended particulate matter flux contained in irrigation waters [43].

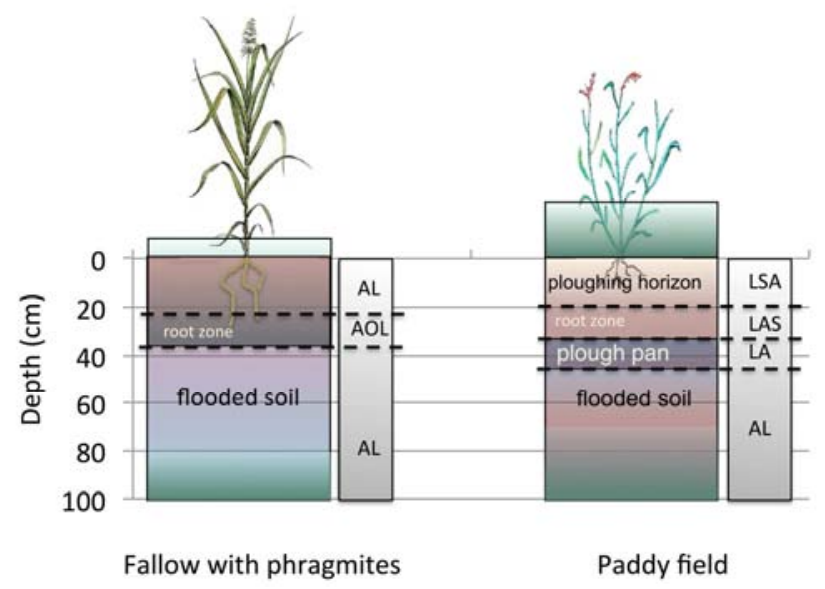

Figure 3. Distribution of soils in natural fallow with phragmites and in paddy field with textural indications: AL: silty clay, ALO: heavy clay, LA: clay loam, LAS: clay sandy loam, LSA: sandy clayey loam.

\subsection{Mineralogy of Clay Minerals}

The clay fraction of the soil of both systems shows the simultaneous presence of illite, kaolinite, chlorite and smectite with additional reflections that are attributed to quartz. This is typical of diagenetic clays from Alps Mountains, which were transported by the Rhône River [43] and accumulated in the recent fan sedimentation [28, 32]. In X-ray diffraction patterns (Fig. 4), the rational (001) reflection series at $14.39 \AA$ and $16.87 \AA$ (EG treated sample) are assigned to smectite, peaks at $14.15 \AA$ (EG treated sample), $9.96 \AA$ and $4.98 \AA$ assigned to illite, while kaolinite is present at positions $10.3 \AA$ (Hy treated sample) and $7.08 \AA$, and chlorite is present at positions 3.54 and $4.70 \AA$. The quartz reflections are found at positions $4.24 \AA$ and $3.34 \AA$.

Fig. 5 and Table 2 show that illite is the most abundant clay and constitute more than $50 \%$ of particles, followed by kaolinite and chlorite; smectites are the least abundant with a quite similar profile in both systems: their quantities increase progressively from 10 to $15 \%$ with depth. At all depths, the abundance of each clay, considered separately, is comparable between the two sites with and, down to $60 \mathrm{~cm}$ depth, the clay-mineral percentages are similar in both systems. 


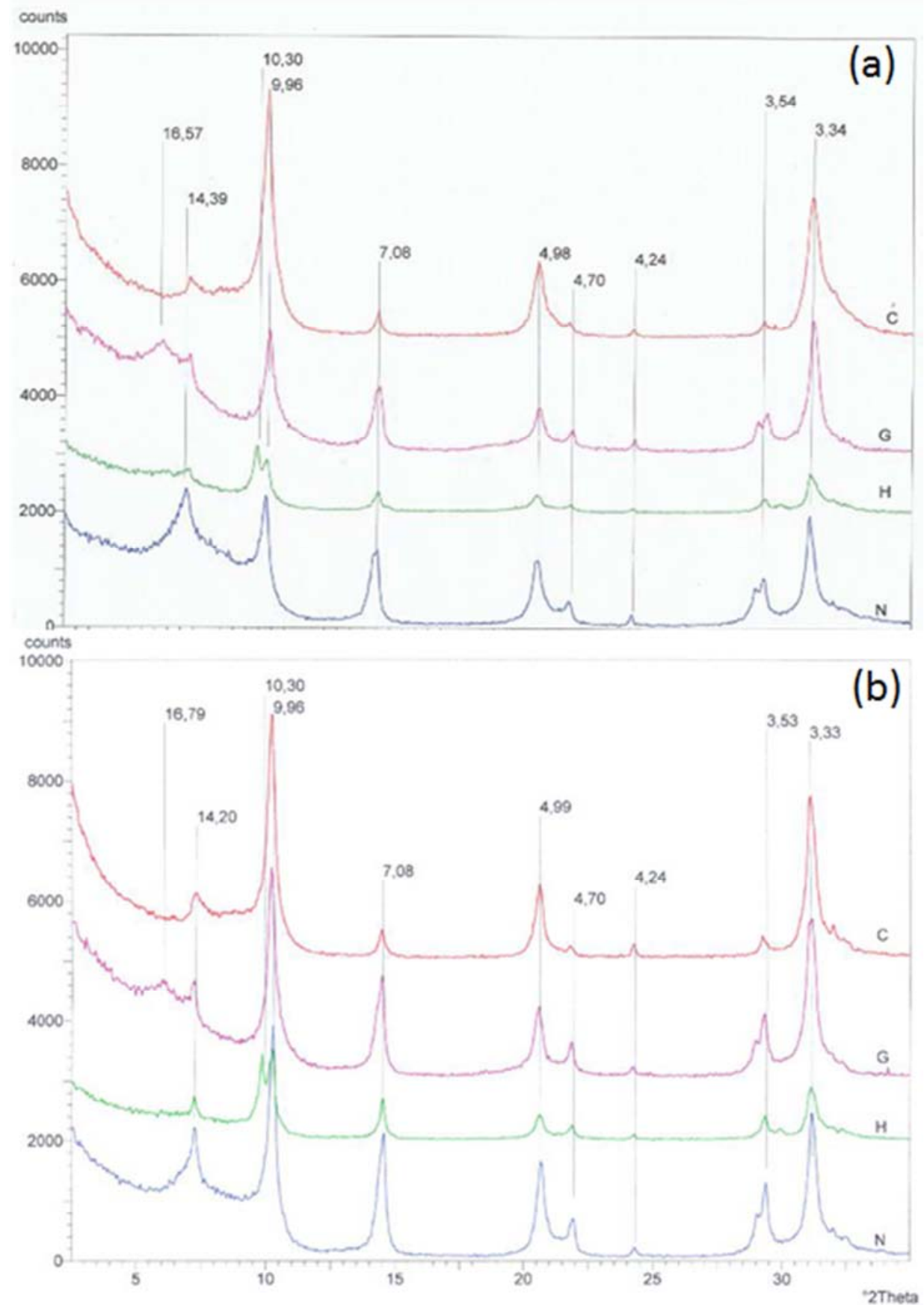

Figure 4. XRD patterns of clay fractions obtained after different treatments of soil samples taken at 0-10 cm (a) in Paddy and (b) Fallow plots. $N=N o$ treatment, $H=$ Hydrazine treatment, $G=$ Ethylene Glycol treatment and $C=$ oven treatment at $490^{\circ} \mathrm{C}$.

Table 2. Distribution (in \%) of the four main clay minerals in the fallow and paddy soils as function of the depth.

\begin{tabular}{lllllll}
\hline System & depth (cm) & Chlorite (\%) & Kaolinite (\%) & Illite (\%) & Smectite (\%) & Total (\%) \\
\hline Fallow & $0-20$ & 14.1 & 17.8 & 57.1 & 10.9 & 99.9 \\
& $20-40$ & 12.7 & 15.6 & 62.2 & 9.4 & 99.9 \\
& $40-60$ & 12.1 & 15.8 & 61.6 & 10.5 & 100.0 \\
& $60-80$ & 9.8 & 22.2 & 51.3 & 16.7 & 100.0 \\
& $80-100$ & 12.5 & 15.3 & 45.5 & 26.7 & 100.0 \\
Paddy & $0-20$ & 12.0 & 27.1 & 54.2 & 6.7 & 100.0 \\
& $20-40$ & 17.4 & 22.0 & 55.0 & 5.5 & 99.9 \\
& $40-60$ & 16.2 & 18.4 & 52.0 & 5.4 & 100.0 \\
& $60-80$ & 12.8 & 21.1 & 44.9 & 22.1 & 99.9 \\
\hline
\end{tabular}




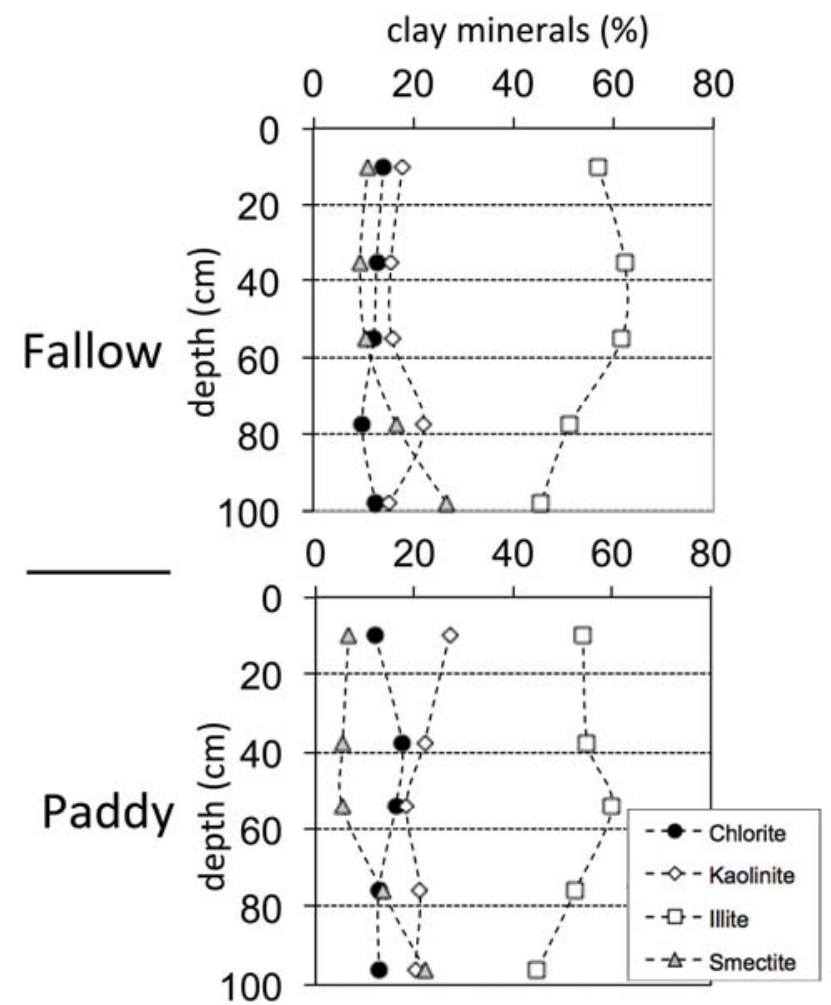

Figure 5. Clay mineral distribution (in \%) in the fallow and paddy fields as function of the depth.

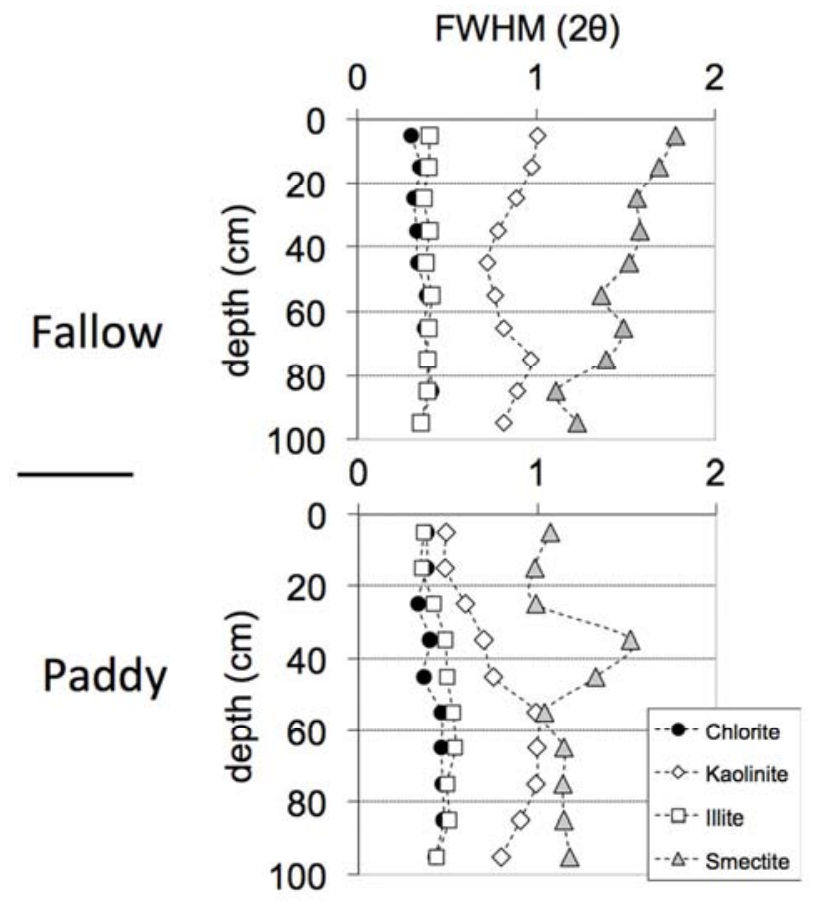

Figure 6. Variations of FWHM parameter for the clay minerals in fallow and paddy fields, respectively.

\subsection{Estimation of the Degree of Crystallization of the Clay Minerals}

Significant changes in the degree of crystallization of the different clay minerals were observed depending on the location in the soil profile and land use (Fig. 6 and Table 3). These results suggest that intensive rice cultivation has significantly changed the crystallisation of the clays in the most weatherable of the ploughed horizon. The rice demand of $\mathrm{Si}$ was fulfilled by smectite and, in a second order by kaolinite, compared to the other clays. We observed first that illite and chlorite are well crystallized and that their degree of crystallization remains constant and of the same magnitude in both systems along the whole soil profile. Moreover, we observed secondly that the degree of crystallization of kaolinite and smectite in the ploughed horizon of the paddy field is significantly larger than in the fallow. We observe thirdly that in the plough pan the FWHM parameter of smectite is of the same order of magnitude than observed at the same depth $(40-50 \mathrm{~cm})$ in the fallow with phragmites. The FWHM of smectite exhibits the larger variability throughout the soil horizon in both the paddy and fallow systems and this large value indicates that smectites are the poorest crystallized clay compared to the other clays. The poor-crystallized smectites are more abundant in the upper 40 $\mathrm{cm}$ of the fallow system than in the paddy horizon. This might be related to chemistry, size and specific surface area particularly of smectites [44]. The expandable layers of this clay provide high surface area for the chemical reactions and thus easier release of nutrients. This explains the cumulative effect with time of this active use of the poorly crystallized clay fractions as a source of Si for rice at each crop. This is consistent with other results obtained indirectly by selective extraction on topsoils of different paddy fields in Asia where the relationships between carbonate-extractable Si form and plant silicon uptake is established and show large regional variations (between 2.2 and $16.7 \mathrm{~g} \mathrm{Si} \mathrm{kg}^{-1}$ ) [45].

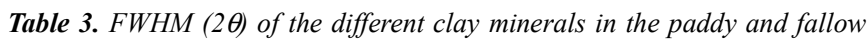
soils as function of depth.

\begin{tabular}{llllll}
\hline & $\begin{array}{l}\text { depth } \\
\text { (cm) }\end{array}$ & FWHM & & & \\
\cline { 3 - 5 } System & Chlorite & Kaolinite & Illite & Smectite \\
\hline & $0-10$ & 0.299 & 1.008 & 0.402 & 1.778 \\
& $10-20$ & 0.351 & 0.973 & 0.399 & 1.687 \\
& $20-30$ & 0.318 & 0.889 & 0.371 & 1.566 \\
& $30-40$ & 0.332 & 0.788 & 0.401 & 1.583 \\
& $40-50$ & 0.336 & 0.726 & 0.383 & 1.522 \\
& $50-60$ & 0.386 & 0.768 & 0.414 & 1.365 \\
& $60-70$ & 0.374 & 0.817 & 0.397 & 1.486 \\
& $70-80$ & 0.392 & 0.972 & 0.390 & 1.389 \\
& $80-90$ & 0.413 & 0.894 & 0.394 & 1.113 \\
& $90-100$ & 0.348 & 0.818 & 0.352 & 1.232 \\
& $0-10$ & 0.380 & 0.489 & 0.364 & 1.073 \\
& $10-20$ & 0.381 & 0.487 & 0.354 & 0.985 \\
& $20-30$ & 0.333 & 0.597 & 0.422 & 0.992 \\
& $30-40$ & 0.397 & 0.699 & 0.484 & 1.523 \\
& $40-50$ & 0.364 & 0.756 & 0.496 & 1.328 \\
& $50-60$ & 0.461 & 0.993 & 0.527 & 1.038 \\
& $60-70$ & 0.463 & 0.997 & 0.541 & 1.147 \\
& $70-80$ & 0.469 & 0.994 & 0.496 & 1.142 \\
& $80-90$ & 0.475 & 0.903 & 0.504 & 1.149 \\
& $90-100$ & 0.429 & 0.797 & 0.435 & 1.183 \\
\hline
\end{tabular}




\subsection{Morphology of Si Particles in Soils}

In the paddy soils, the clay mineral crystallites are large, well-formed and polygonal textured (Fig. 7a), whereas, in the fallow, they are poorly crystallized (Fig. 7b), and associated with forms of diatomaceous tests, sponge spicules and phytoliths (opal-A structure) (Fig. 7c). Some of the phytholiths structures are heavily corroded, indicating a preferential dissolution of the biogenic silica (BSi) compartment in the paddy soil [42].

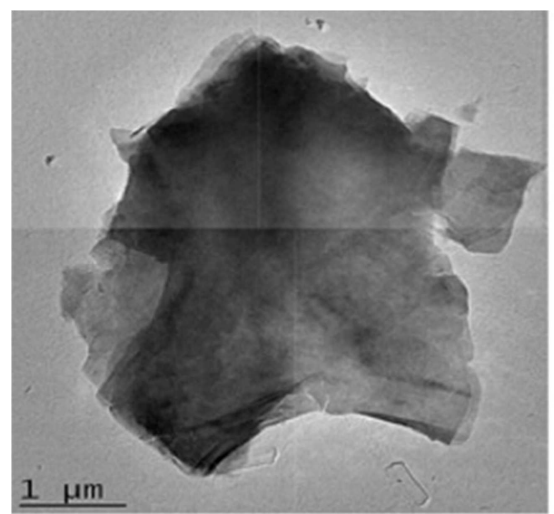

(a)

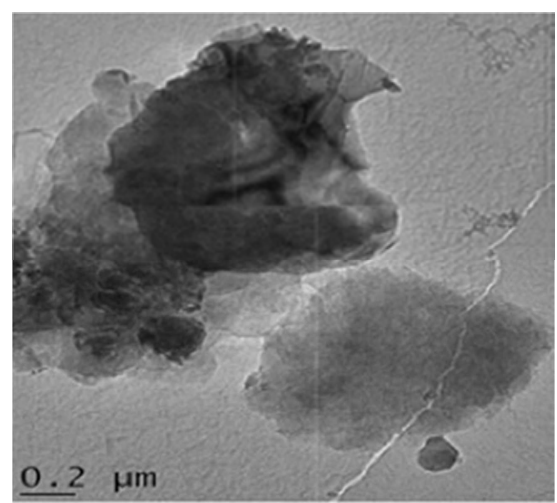

(b)

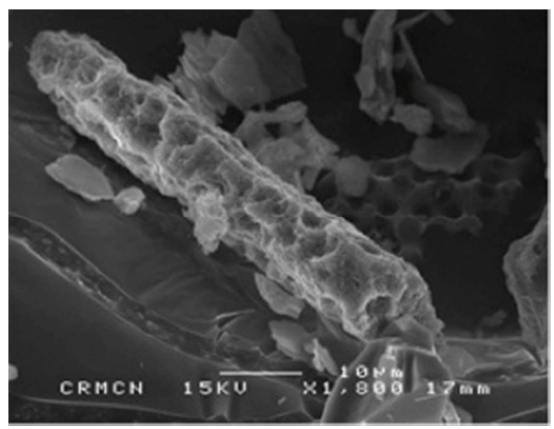

(c)

Figure 7. Sources of Si in soils with an increased bioavailability: (a) well crystallized clay characterized by well defined edges (paddy field); (b) poor crystallized clay characterized by blurred and rounded edges (fallow with phragmites) and, (c) phytolith of cereals showing numerous weathering pits (paddy field).

\subsection{Towards the Need for a Siliceous Fertilization}

The question of siliceous fertilization arose in the 1950s in Japan, because the soils of rice fields, of volcanic origin, are naturally poor in silica [21]. Thus, the maintenance of siliceous fertility was ensured, either by the supply of rice straw compost, i.e. organic silica, or more recently by steel mill slags in the form of $\mathrm{CaSiO}_{2}$; the quantities of silica supplied varying from 200 to $600 \mathrm{~kg} \mathrm{Si} /$ ha / year [19].

Recent works (see references included in [18]) show that for rice cultivation, the form "composted rice straw" appears to be a more efficient silica source than all other forms of vegetable compost, although technically the straw is rich in silica, less it is digestible for cattle or sheep and more difficult it is composting. Another interesting source of silica may be, after conditioning the rice in the flourmill, the recovery and return to the field of the cuticles of the grain. Finally, other pathways are explored in the genetics of rice where six QTLs (Quantitative Trait Loci) coinciding with Si content markers have been observed. When the genes carrying these QTLs are identified, it will be possible to understand the mechanisms regulating the status of $\mathrm{Si}$ in the plant and to accelerate the reproduction of the associated traits in new cultivars.

In the Camargue, the reserve of mineral silica of poorly crystallized clays of the soil has been greatly solicited and reduced by the practice of a rice growing without siliceous fertilization for more than 60 years. Pending the proposal for new rice cultivars on market more efficient to uptake Si from soils, the sustainability of the system must now be driven, at minimum, through the careful management of straw and mill residues in order to ensure return to the field at the right time in the crop cycle of rice of Si needed by the plant. If this balance remains deficient, then other sources of $\mathrm{Si}$ to be applied in the fields should be sought and added together with the other fertilizers.

\section{Conclusion}

The mineralogical pattern of Camargue's soils has been influenced by intensive rice cultivation for the last 60 years. The reduction in yield of some varieties, which were previously well adapted suggests the decrease of $\mathrm{Si}$ availability from soils. These results point out the importance of the $\mathrm{Si}$-cycle for the sustainability of rice cultivation and especially the role of poorly crystallized clay fractions and of biogenic $\mathrm{Si}$.

XRD studies of the clay fraction reveal that the main clay minerals are illite, kaolinite, chlorite and smectite. DecompXR analysis shows that the degree of crystallization of smectite in the soil profile is particularly affected by the intensive rice cultivation as compared to the fallow field. As the degree of crystallization of fine clay minerals increases, the bioavailability of silica from the soil minerals decreases, because the remaining forms of silicon minerals are less soluble. In the fallow, phytoliths are continuously renewed and dissolved, protecting smectites, while in the paddy soils, 
phytoliths are progressively dissolved; then smectites and to a lesser extent kaolinite dissolve to supply large $\mathrm{Si}$ rice requirements. This can ultimately lead to deficiencies that could impact crop yields if silicon fertilization is not considered.

\section{Acknowledgments}

Support of High Education Commission of Pakistan government for financial grants for Irfan Kamran and Tanvir Shahzad, of French Minister of National Education and Research for $\mathrm{PhD}$ Grant for Lise Cary are gratefully acknowledged. The authors thank Daniel Borschneck and Monique Mayor for their technical support, Bruno Lanson for his help on DecompXR software and Xavier Guillot from Mejanes Domain in Camargue for the access to the fields and many fruitful discussions. The authors also thank the two anonymous reviewers, who contributed by their suggestions to improve the quality of the paper.

\section{References}

[1] OCDE/Organisation des Nations Unies pour l'alimentation et l'agriculture, 2014. Perspectives agricoles de l'OCDE et de la FAO 2014, Éditions OCDE.

[2] Williams, R. J. P., Fraùsto da Silva, J. J. R., 1997. The natural selection of the chemical elements - The environment and Life's chemistry, Clarendon Press, Oxford.

[3] Dove, P. M., Eston, S. F., 1992. Dissolution kinetics of quartz in sodium chloride solutions: analysis of existing data and a rate model for $25^{\circ} \mathrm{C}$. Geochim. et Comoschim. Acta, 56, $4147-4156$.

[4] Song, Z., Müller, K., Wang, H., 2014. Biogeochemical silicon cycle and carbon sequestration in agricultural ecosystems. Earth-Science Reviews, 139, 268-278.

[5] Gascho, G. J., 2001. Chapter 12: Silicon sources for agriculture. In: L. E. Datnoff, G. H. S., Korndörfer, G. H. (Eds.), Studies in Plant Science. Elsevier, 197-207.

[6] Matichenkov, V. V., Bocharnikova, E. A., 2001. The relationship between silica and soil physical and chemical properties. In: Datnoff, L. E., Snyder, G. H., Korndörfer, G. H. (Eds.), Silicon in Agriculture. Elsevier, Amsterdam, Netherlands, 209-215.

[7] Alexandre, A., Meunier, J. D., Colin, F., Koud, J. M., 1997. Plant impact on the biogeochemical cycle of silicon and related weathering processes. Geochim. et Cosmochim. Acta, 61, 677-682.

[8] Derry, L. A., Kurtz, A. C., Ziegler, K., Chadwick, O. A., 2005. Biological control of terrestrial silica cycling and export fluxes to watersheds. Nature 433: 728-731.

[9] Lindsay, W. L., 1979. Chemical equilibria in soils. Widley J \& Hoboken NJ eds, 449 pp.

[10] Loucaides, S., Behrends, T., Van Cappellen, P., 2010. Reactivity of biogenic silica: Surface versus bulk charge density. Geochim. et Cosmochim. Acta, 74, 517-530.
[11] Bartoli, F., Wilding, L. P., 1980. Dissolution of biogenic opal as function of its physical and chemical properties. Soil Sci. Soc. Amer. J., 44, 873-878.

[12] Fraysse, F., Pokrovsky, O. S., Schott, J., Meunier, J. D., 2009. Surface chemistry and reactivity of plant phytoliths in aqueous solutions. Chemical Geology, 258, 197-206.

[13] Jones, L. H. P., Handreck, K. A., 1967. Silica in soils, plants and animals. Advances in Agronomy, 19, 107-149.

[14] Armitage, P. L., 1975. The extraction and identification of opal phytoliths from the teeth of ungulates. Journal of Archaeological Science, 2(3), 187-197.

[15] Blecker, S. W., McCulley, R. L., Chadwick, O. A., Kelly, E. F., 2006. Biologic cycling of silica across a grassland bioclimosequence. Global Biogeochem. Cycles, 20, GB3023, doi: 10.1029/2006GB002690.

[16] Clymans, W., Struyf, E., Govers, G., Vandevenne, F., Conley, D. J., 2011. Anthropogenic impact on amorphous silica pools in temperate soils. Biogeosciences, 8, 2281-2293.

[17] Epstein, E., 1994. The anomaly of silicon in plant biology. Proceedings of the National Academy of Sciences of the United States of America, 91, 11-17.

[18] Meharg, C., Meharg, A. A. 2015. Silicon, the silver bullet for mitigating biotic and abiotic stress, and improving grain quality, in rice ? Environmental and Experimental Botany, $120,8-17$

[19] Ma, J., Takahashi, E., 2002. Soil, fertilizer and plant silicon research in Japan. Elsevier ed.

[20] Lucas, Y., Luizao, F. J., Chauvel, A., Rouiller, J., Nahon, D., 1993. The relationship between the biological activity of the rain forest and the mineral composition of the soils. Science, 260, 521-523.

[21] Dahlgren, R. A., Shoji, S., Nanzyo M., 1993. Mineralogical characteristics of volcanic ash soils, in "Volcanic Ash Soils, Genesis, Properties and Utilization", edited by S. Shoji et al., Elsevier, New York, 101- 145.

[22] Kelly, E. F., Chadwick, O. A., Hilinski, T. E., 1998. The effect of plants on mineral weathering, Biogeochemistry, 42, 21- 53.

[23] Savant, N. K., Datnoff, L. E., Snyder, G. H., 1997. Depletion of plant-available silicon in soils: A possible cause of declining rice yields. Communications in Soil Science and Plant Analysis, 28, 1245-1252.

[24] Guntzer, F., Keller, C., Poulton, P. R., McGrath, S. P., Meunier, J. D., 2012. Long-term removal of wheat straw decreases soil amorphous silica at Broadbalk, Rothamsted. Plant and Soil, 352, 173-184.

[25] Kraska, J. E., Breitenbeck, G. A., 2010. Survey of the silicon status of flooded rice in Louisiane. Agron. J., 102, 523 - 529.

[26] Chauvelon, P., Tournoud, M. G., Sandoz, A., 2003. Integrated hydrological modelling of a managed coastal Mediterranean wetland (Rhone delta, France): initial calibration. Hydrology and Earth System Sciences, 7, 123-131.

[27] Mouret, J. C., 2004. Les potentialités agroclimatiques et la place du riz dans la dynamique d'évolution des systèmes de culture en Camargue. Conférence donnée à Agropolis $\begin{array}{lllll}\text { Museum } & \text { le } & 6 & \text { octobre } & 2004 .\end{array}$ http://www.museum.agropolis.fr/pages/savoirs/camargue/. 
[28] Boutheyre, G., Duclos, G., 1994. Carte pédologique de France au 1/100 000, Arles N-22. Service d'Etude des Sols et de la Carte pédologique de France, Orléans, France.

[29] Irfan, K., 2013. Adaptation of the generic crop model STICS for rice (Oryza sativa L.) using farm data in Camargue. Thesis $\mathrm{PhD}$. Aix Marseille University, Marseille, France.

[30] Cary, L., 2005. Mobilité des éléments selon les alternances d'aérobie-anaérobie dans un écosystème rizicole en Camargue, Thèse de Doctorat, Aix-Marseille University.

[31] Cary, L., Trolard, F., 2006. Effects of irrigation on geochemical processes in a paddy soil and in groundwater in Camargue (France). J. Geochem. Explor., 88, 177-180.

[32] Vella, C. 1999. Perception et évaluation de la mobilité du littoral sur la marge orientale du delta du Rhône. PhD thesis, Université de Provence, Marseille, France.

[33] Shrivastava, V. S., 2009. X-ray Diffraction and Mineralogical Study of Soil: A Review. J. Applied Chem. Res., 9, 41-51.

[34] Wada, K., Yamada, H., 1969. Hydrazine intercalationinterstalation for differenciation of kaolin minerals from chlorites. Am. Miner., 4, 334-339.

[35] Bradley, W., 1945. Molecular associations between montmorillonite and some polyfunctional organic liquids. J. Amer. Chem.Soc., 67, 975-981.

[36] DecompXR, 2015. Decomposition program is available for download from:

$\mathrm{http}: / /$ www.isterre.fr/spip.php?action=acceder_document\&doc ument\&arg $=3132 \& \mathrm{cle}=\mathrm{a} 38112 \mathrm{~d} 2714 \mathrm{a} 366402$ fed5b6b16ddf3a 6be96ae3\&file=zip\%2FDecompXR.zip.

[37] Lanson, B., 1997. Decomposition of experimental x-ray diffraction patterns (profile fitting): A convenient way to study clay minerals. Clays \& Clay Miner., 45, 132-146.
[38] Lanson, B., 1990. Mise en évidence des mécanismes de transformation des interstratifiés illite/smectite au cours de la diagenèse. $\mathrm{PhD}$ thesis, Paris University, France.

[39] Kelly, E. F., 1990. Methods for extracting opal phytoliths from soil and plant material. Doc. of the Department of Agronomy, Colorado State University, 10pp.

[40] Cary, L., Alexandre, A., Meunier, J. D., Boeglin, J. L., Braun, J. J., 2005. Contribution of phytoliths to the suspended load of biogenic silica in the Nyong basin rivers (Cameroon). Biogeochemistry, 74, 101-114.

[41] Nawaz, F. M., Bourrié, G., Trolard, F., 2013. Soil compaction impact and modeling: A review. Agronomy for Sustainable Development, doi: 10.1007/s13593- 011-0071-8.

[42] Desplanques, V., Cary, L., Mouret, J. C., Trolard, F., Bourrié, G., Grauby, O., Meunier, J. D., 2006. Silicon transfers in a rice field in Camargue (France). J. Geochem. Explor., 88, 190-193.

[43] Ollivier, P., Hamelin, B., Radakovitch, O., 2010. Seasonal variations of physical and chemical erosion: a three-year survey of the Rhône River (France). Geochim. et Cosmochim. Acta, 74, 907-927.

[44] Tournassat, C., Gailhanou, H., Crouzet, C., Braibant, G., Gautier, A., and Gaucher, E. C., 2009. Cation Exchange Selectivity Coefficient Values on Smectite and Mixed-Layer 1llite/Smectite Minerals. Soil Science Society of America Journal of Agricultural Meteorology, 73, 928-942.

[45] Klotzbücher, T., Marxen, A., Jahn, R., Vetterlein, D., 2016. Silicon cycle in rice paddy fields: insights provided by relations between silicon forms in topsoils and plant silicon uptake. Nutr Cycl Agroecosyst, doi: 10.1007/s10705-0169782-1. 